\title{
Impact of distance learning on the health of students at pedagogical universities
}

\author{
Natalya Arkadyevna Zakorkina ${ }^{11}$, Olga Ivanovna Kurdumanova ${ }^{2}$, Larisa Aleksandrovna \\ Zharkikh$^{2}$, and Irina Borisovna Gilyazova ${ }^{2}$ \\ ${ }^{1}$ Omsk State Pedagogical University, Department of Life Safety Fundamentals and Methods of \\ Teaching Biology, Omsk, Russia \\ ${ }^{2}$ Omsk State Pedagogical University, Department of Chemistry and Methods of Teaching Chemistry, \\ Omsk, Russia
}

\begin{abstract}
In recent years, the problem of deteriorating health of students studying in a distance format has been very urgent. On the one hand, the volume of the teaching load, including interesting educational programs in the online format, is increasing; on the other hand, there are no sanitary rules governing the requirements for the educational process in universities. The research purpose is to establish the features of health disorders of distance learning students. A survey was conducted among full-time and distance learning students. Through the analysis of variance, the strength of the impact of each factor related to deviations in students' health was determined. Statistical reliability was confirmed using variance and special tables. The conducted research identified informatively significant factors related to health deviations of distance learning students. The analysis of variance was used to assess the influence of factors and their strength. Reliability of the impact of factors was determined using variance and special tables. The results are reliable $(p<0.001)$. The available literary sources do not cover the problem of ranking the leading factors. Among them, a decrease in physical activity, emerging sub-health forms, visual impairments, changes in the general psychoemotional state are of particular importance. The following conclusions can be done. The revealed features of health disorders in distance learning students are associated with a decrease in physical activity, the development of hypodynamia, emerging sub-health states, visual impairment, a change in the general psychoemotional state. The distance learning process shall be regulated by Sanitary Rules and Regulations developed for universities.
\end{abstract}

Keywords: health disorders, distance format, physical activity, hypodynamia, health of students

\section{Introduction}

The problem of deteriorating health of children and adolescents in the context of distance learning is of particular relevance [1]. First of all, this concerns first-year students who are

${ }^{1}$ Corresponding author: zakorkina53@mail.ru 
switching to a new form of study - studies at university. An even more negative risk factor is an online format [2].

In the absence of a regulatory framework that regulates sanitary and hygienic requirements for the educational process, adaptation to a new form of study is accompanied by health disorders [3].

The process of creating and implementing electronic educational resources (EERs) is based on special requirements underlying their development [4]. Since EERs are considered one of the important components of modern education, responsible for mastering the theoretical and practical course material with high intensity, clarity, increased strength, level and quality of acquired educational knowledge, they need to meet a system of numerous requirements, including psychological and ergonomic ones [5].

The quality of creation of electronic educational resources and the success of their implementation in the educational process is influenced by the incorporation and fulfillment of psychological requirements. According to the psychological requirements, the educational material in EERs should correspond to the sensory-perceptual and representational levels of the cognitive process in students. This means that the creation of EERs is based not only on the verbal-logical aspect, but also on taking into account the peculiarities of cognitive mental processes (visual, auditory, tactile perception; attention; thinking; memory; imagination) [6].

Ergonomic requirements are as follows: taking into account students' peculiarities (age, individual ones), the use of various types of organization of educational activities; increasing the level of motivation for learning due to additional incentives when a student uses electronic educational resources; the design, display and presentation of information should comply with the recommended criteria for the development of EERs (color scheme, legibility, image clarity) [7].

In a short period of distance learning, sub-health forms of health disorders are formed [8]. Some authors recommend paying attention to students' psycho-emotional state, which is rapidly changing in the course of distance learning [9].

Research purpose: to establish the features of health disorders in distance learning students.

Research objectives. To study the significance of various deviations in students' health in the context of distance learning at a pedagogical university.

\section{Methods}

In this study, a special questionnaire consisting of 2 groups of factors was used:

The first group includes factors related to distance learning, for example: duration of work at the computer, the volume of study load, workplace arrangement, lighting, use of computer technology without Internet restrictions, the level of mastering the educational material, etc. [10].

The second group includes factors related to health disorders: visual impairment, emerging stress, sub-health states, sleep disturbances, changes in the psychoemotional state, exacerbation of chronic diseases, etc. [11].

The control group consisted of first-year full-time students enrolled in 2019 - they filled out only the second part of the questionnaire. The study group includes first-year distance learning students enrolled in 2020. A total of 98 and 102 people, respectively.

The analysis of variance was used to assess the impact of factors and their strength. Several values were assigned to each studied factor; each factor was divided into gradations in accordance with the values [12]. 
For example, the factor "Emerging stress" had the following gradations: I had no stress; stress appeared at the beginning of distance learning; I was stressed out due to the upcoming final attestation; I had panic behavior during the entire period of study.

The factor "Duration of work at the computer" - up to 8 hours; up to 10 hours and more than 10 hours, etc.

Reliability of the impact of factors was determined by using variance and special tables.

Students' health disorders as an effective feature are influenced by many factors that cannot be taken into account in one study. Therefore, when conducting the analysis of variance, organized factors are determined, in this case these are all components of distance learning (increased computer load, static posture, etc.). If it is possible to prove the impact of organized factors, it can be argued that they have an effect on the studied feature, in this case - health disorders, if it is not possible, then the main influence is exerted by unorganized factors, i.e. those that are not taken into account. The analysis of variance consists of several stages: the construction of a dispersion complex, calculations, determination of impact strength and assessment of reliability of impact strength [13]. In the analysis of variance, the total variance of feature $\mathrm{C} \gamma$ in the study group is divided into variance caused by the influence of organized factors $\mathrm{Cx}$ and variance caused by unorganized factor $\mathrm{Cz}$. The ratio of $\mathrm{Cx}$ to $\mathrm{C} \gamma$ and $\mathrm{Cz}$ to $\mathrm{C} \gamma$ shows the share of participation of each factor and determines the correlation ratio of impact of organized factors $\left(\eta^{2} x\right)$ and unorganized factors $\left(\eta^{2} \mathrm{z}\right)$.

If $\eta^{2} x$ was 0.30 , this means that the influence of organized factors will be $30 \%$ and unorganized ones $-70 \%$.

To assess the reliability of the results, the Fisher's criterion $(\mathrm{F})$ is calculated and its value is compared with the tabulated one. If the actual value of the criterion exceeds the tabulated one, the degree of probability is determined.

\section{$3 \quad$ Results}

The analysis of variance made it possible to rank the factors by strength of their impact and highlight the most significant characteristics (Table 1).

Table 1. The most informative factors associated with health disorders in distance learning students.

\begin{tabular}{|l|c|c|}
\hline \multicolumn{1}{|c|}{ Factors } & $\begin{array}{c}\text { The share of factor } \\
\text { contribution to the } \\
\text { total variance }\end{array}$ & $\begin{array}{c}\text { Ranking place of } \\
\text { factors }\end{array}$ \\
\hline Visual impairment & $38.4 \%$ & 3 \\
\hline $\begin{array}{l}\text { Sub-health states (pain in the neck, back, } \\
\text { wrist, headache, fatigue, heart } \\
\text { palpitations, high blood pressure, etc.) }\end{array}$ & $42.3 \%$ & 2 \\
\hline Decreased physical activity & $51.2 \%$ & 1 \\
\hline Emerging stress & $6.5 \%$ & 9 \\
\hline $\begin{array}{l}\text { Behavior instability (irritability, inability } \\
\text { to control one's own emotions) }\end{array}$ & $28.3 \%$ & 8 \\
\hline $\begin{array}{l}\text { Exacerbation of underlying chronic } \\
\text { diseases }\end{array}$ & $9.1 \%$ & 7 \\
\hline Sleep disturbance & $12.7 \%$ & 6 \\
\hline Meal frequency & $14.9 \%$ & 4 \\
\hline $\begin{array}{l}\text { Change in the general psychoemotional } \\
\text { state associated with an imbalance } \\
\text { between the positive and the negative }\end{array}$ & $29.4 \%$ & 8 \\
\hline
\end{tabular}


The data obtained as a result of the analysis cannot be summed up, since they were taken on the basis of different dispersion complexes. Some factors do not have a high impact, but are reliable in all cases $(\mathrm{p}<0.001)$.

\section{Discussion}

Hypodynamy (51.2\%) had a more pronounced effect on the health impairment of distance learning students. A decrease in physical activity and limited walks in the fresh air are regarded by many authors as a sign of a decrease in reserve capacities of the body, which means the occurrence of diseases and functional disorders [14].

The second rank is occupied by the factor "Sub-health states" (42.3\%). Fatigue due to static posture usually leads to the onset of symptoms of the musculoskeletal and cardiovascular systems [8].

The third rank is accompanied by the factor "Visual impairment" (38.4\%). Prolonged visual fatigue, accompanied by a burning sensation, sandy-gritty sensation and seeing spots in the eyes, leads to a lack of refractive power of the eyes and vision deterioration, this is the so-called computer visual syndrome [15].

The fourth and fifth ranks characterize changes in the general psychoemotional state and the irritability and inability to control one's own emotions acquired during the training $29.4 \%$ and $28.3 \%$, respectively [9].

Factors, including those associated with disturbances in the meal frequency and sleep duration, have been and remain statistically significant and reliable [2].

\section{Conclusion}

1. The revealed features of health disorders in distance learning students are associated with a decrease in physical activity, the development of hypodynamia, emerging sub-health states, visual impairment, a change in the general psychoemotional state.

2. The distance learning process should be regulated by the Sanitary Rules and Regulations developed for universities.

\section{References}

1. S. Aggarwal, et al., J. Psychiatric Stud 1(1), 104 (2021). https://doi.org/10.31021/jps.20201104

2. J. Mangis, EWU Masters Thesis Collection, 386 (2016). Accessed on: July 22, 2021. [Online]. Available: http://dc.ewu.edu/theses/386

3. V.R. Kuchma, et al., Iss. Sch. Univ. Med. Health 2, 4-23 (2020)

4. E. Armstrong-Mensah, K. Ramsey-White, B. Yankey, Sh. Self-Brown, Front. Pub. Health, 8, 1-10 (2020). https://doi.org/10.3389/fpubh.2020.576227

5. E. Akpınar, The Europ. J. Soc. Beh. Sci., 30, 3300-3310 (2021). https://doi.org/10.15405/ejsbs. 288

6. F. Garivaldis, Transcending “Distance” in Distance Education, in Tertiary Online Teaching and Learning, 137-147, (2020). https://doi.org/10.1007/978-981-15-8928-7_12 
7. A.D. Dumford, A.L. Miller, J. Comp. Higher Edu., 30, 452-465 (2018). https://doi.org/10.1007/s12528-018-9179-z

8. V.V. Chubarovskii, J. Health Pol. Manag. 3, 32-33 (2020)

9. V.G. Sokolov, Mod. Edu. 1, 1-13 (2014). https://doi.org/10.7256/2306-4188.2014.1.10921

10. C. Halupa, Risks: the impact of online learning and technology on student physical, mental, emotional, and social health, in ICERI2016 Proceedings 9th annual, International Conference of Education, Research and Innovation, 14-16 November, 2016 Seville, Spain, 6305-6314 (2016). https://doi.org/10.21125/iceri.2016.0044

11. M. John, D.K. Sharma, J. Abraham, V.A. Konuri, National J. Clin. Anat. 10, 10-16 (2021). https://doi.org/10.4103/NJCA.NJCA_12_20

12. J.D. Daniel, Analysis of Variance, in Applied Univariate, Bivariate, and Multivariate Statistics Using Python, 113-147 (Wiley, 2021). https://doi.org/10.1002/9781119578208.ch6

13. P. Schober, Th. Vetter, Anesthesia and analgesia, 131, 508-509 (2020). https://doi.org/10.1213/ANE.0000000000004839

14. S.W.H. Kwok, P.H. Lee, R.L.T. Lee, Int. J. Envir. Res. Pub. Health 14(2), 205 (2017)

15. S.N. Korotkikh, A.A. Nikiforova, M.S. Andreeva, Mod. Optometry, 2(10), 30-34 (2017) 